\title{
Early start of the West Nile fever transmission season 2018 in Europe
}

Joana M. Haussig ${ }^{1,2}$, Johanna J. Young ${ }^{1,2}$, Céline M. Gossner'1, Eszter Mezei ${ }^{3}$, Antonino Bella ${ }^{4}$, Anca Sirbu ${ }^{5}$, Danai Pervanidou Mitra B. Drakulovic ${ }^{7}$, Bertrand Sudre ${ }^{1}$

1. European Centre for Disease Prevention and Control (ECDC), Solna, Sweden

2. These authors contributed equally to this article and share first authorship

3. Ministry of Human Capacities, Budapest, Hungary

4. Department of Infectious Diseases, Istituto Superiore di Sanità (ISS), Rome, Italy

5. National Institute of Public Health, Bucharest, Romania

6. Hellenic Center for Disease Control \& Prevention, Marousi, Greece

7. National Institute of Public Health "Dr Milan Jovanovic-Batut", Belgrade, Serbia

Correspondence: Joana M. Haussig (Joana.Haussig@ecdc.europa.eu)

In Europe, surveillance indicates that the 2018 West Nile fever transmission season started earlier than in previous years and with a steeper increase of locallyacquired human infections. Between 2014 and 2017, European Union/European Economic Area (EU/EEA) and EU enlargement countries notified five to 25 cases in weeks 25 to 31 compared with 168 cases in 2018 . Clinicians and public health authorities should be alerted to ensure timely implementation of prevention measures including blood safety measures.

During the West Nile fever (WNF) transmission season in Europe lasting from June to November, European Union/European Economic Area (EU/EEA) and EU enlargement countries monitor the occurrence of all probable and confirmed human WNF cases [1]. The observed occurrence of an unusually early start of the transmission season and the increase in the number of locally-acquired human cases this year prompted us to investigate this signal (excluding asymptomatic cases among blood donors) in comparison with previous seasons and assess the public health implications.

\section{Description of the start of the West Nile fever season 2018}

Between 2014 and 2018, EU/EEA and EU enlargement countries (Austria, Bulgaria, Croatia, Cyprus, France, Greece, Hungary, Italy, Kosovo*, Portugal, Romania, Spain, Serbia and Turkey) reported locally-acquired WNF cases. WNF follows a seasonal pattern with most cases acquired in the countries above reported between July and October, with the case numbers usually peaking between mid-August and mid-September (Figure 1). In the previous two years (2016 and 2017), the first cases during the WNF transmission season were notified from week 28 onwards (Figure 1).
In 2018 , the first WNF cases were notified by Greece in week 26 (25 June to 1 July), with the earliest disease onset on 31 May (week 22). Additionally, we observed an apparent steeper increase of reported case numbers in this season compared with previous years (Figure 1). Between 2014 and 2017, five to 25 cases were notified from week 25 to week 31, in marked contrast to 168 cases reported in the same time period in 2018 by EU/ EEA and EU enlargement countries.

Compared to the six-week period after the initial case report for each year since 2014, the number of cases reported in 2018 is above previous years, with 168 cases in 2018 in comparison with eight in 2014, two in 2015, 62 in 2016 and 66 in 2017.

In 2018 , the yearly median age of cases is 66 years and the sex ratio (male: female) is 2.1 among cases reported to date. Both values are comparable to those in the previous four years (median age between 64.5 and 68 years and sex ratio between 1.3 and 2.4).

As in previous years, Greece has reported the identification of West Nile virus lineage 2 (WNV-2) in 2018, which has been identified regularly throughout south, east and central Europe since its first detection in 2008 in Hungary [2].

Data reported to the Animal Disease Notification System (ADNS) of the European Commission also indicate an early start of the transmission season in 2018 among equids, with six outbreaks among equids between week 26 and week 31 reported by Hungary (3 outbreaks), Greece (2 outbreak) and Italy (1 outbreak). In comparison, one to two outbreaks were reported in the same time period between 2014 to 2016. In 2017, 


\section{FIGURE 1}

Number of West Nile fever cases in European Union/ European Economic Area (EU/EEA) and EU enlargement countries by epidemiological week of notification ${ }^{\mathrm{a}}$, 2014-2018 $(\mathrm{n}=943)$

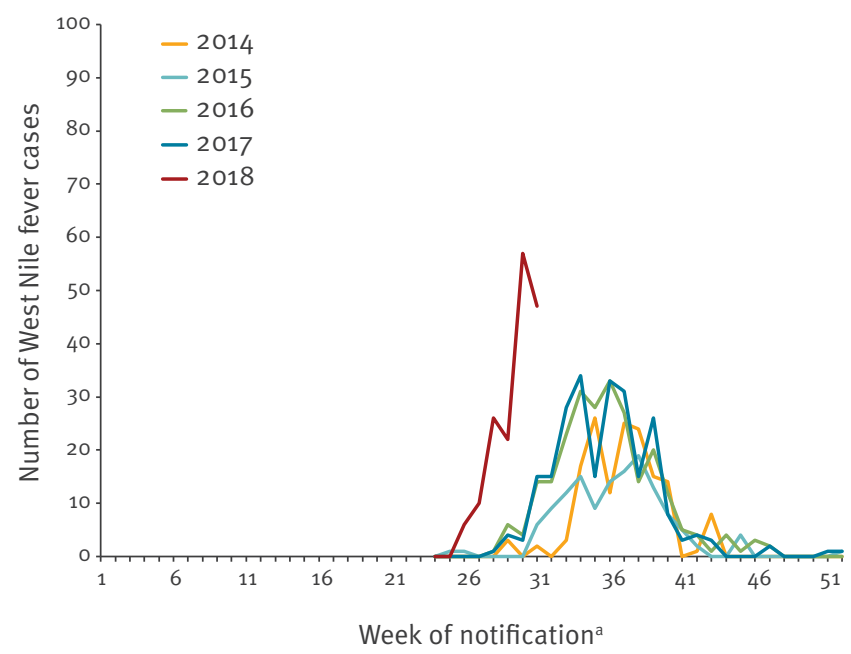

${ }^{\text {a }}$ Week of notification to national authorities or if missing, week of notification to the European Centre for Disease Prevention and Control (ECDC).

10 outbreaks were reported in the same period by Italy and Greece.

Since the beginning of 2018 and as at 3 August, among the 168 human cases reported, 98 have been reported by EU/EEA countries including Greece (43 cases), Italy (38), Hungary (10), and Romania (7). Italy reported two deaths. Furthermore, in the EU enlargement countries 70 human cases, including four deaths, have been reported, all by Serbia (Figure 2 ).

Real-time WNF surveillance is highly dependent on timely reporting of cases and completeness of data such as the date of onset. To verify that the higher number of cases earlier in the season is not caused by faster reporting, or biased by missing weeks of onset (62 missing weeks of onset for 2014), we analysed cumulative case numbers by week of disease onset (Figure $3 \mathrm{~A}$ ), as well as by week of reporting to the national level, or if missing, by week of notification to the European Centre for Disease Prevention and Control (ECDC) (Figure 3B). Both analyses show a similar pattern, with the only difference being that for analyses by week of onset the cumulative endpoint of number of cases is lower due to exclusion of cases with missing weeks of onset. This is an indication that the current WNF season truly started earlier and this cannot be explained by faster reporting.

\section{Geographical distribution}

So far, the majority of the cases in 2018 were reported from previously affected regions at Nomenclature of Territorial Units for Statistics (NUTS) 3 level between
2014 and 2017, with an exception of few areas in Greece. The early affected regions at NUTS 3 level in 2018 are mostly regions that had already reported cases at least three or four times between 2014 and 2017 (Figure 4).

\section{Public health implications}

WNF is a vector-borne disease caused by a flavivirus that is mostly transmitted through bites of Culex mosquitoes. It can also be transmitted through organ transplantation, blood transfusion, from mother to foetus during pregnancy and in laboratory settings [3]. In Europe, WNV has caused both sporadic cases as well as large outbreaks of WNF among humans [4-6].

Real-time monitoring of WNF cases is instrumental to ensure that clinicians and public health authorities are informed about WNV transmission and receive early warnings about unusual seasonal patterns. This also ensures that blood safety measures are implemented in a timely manner to avoid infections through blood transfusions. According to the Commission Directive 2014/110/EU, prospective blood donors should be deferred for 28 days after leaving a risk area of locally acquired WNV unless the result of an individual nucleic acid test (NAT) is negative [7]. In order to assist national authorities in implementing these measures, including for travellers returning from risk areas, ECDC publishes weekly updated maps of human WNF cases at the NUTS 3 level during the WNF transmission season [8]. Moreover, these reports define the geographical areas for which persons residing or visiting, and especially persons at higher risk of severe WNF (i.e. the elderly and immunocompromised) should be promptly informed about the preventive measures to reduce mosquito biting such as use of mosquito repellent and adequate clothing.

According to monthly summaries of Copernicus Climate Change Services, a European system that monitors environmental and societal challenges associated with human-induced climate changes, the average precipitation observed in March 2018 was above the 19812010 period average in many parts of Europe, notably in the WNF affected areas [9]. In April 2018, the surface air temperatures presented a marked anomaly above average while precipitation was almost normal. Temperatures in May 2018 were also higher than the 1981-2010 average in the WNF affected areas. Of note, precipitation in Italy and the countries along the Adriatic coast was much above average in May. June 2018 saw precipitation much above the average in most of southern Europe, and in particular, in the countries along the Adriatic coast, with floods in several regions, including in Greece and Romania [9].

This observed weather pattern is indicative of an early spring season in the south-eastern part of Europe and might have sustained environmental conditions favouring an early upsurge of the vector population. This is confirmed by the recent observation from the Serbian 


\section{FIGURE 2}

Number of West Nile fever cases by week of notification ${ }^{a}$ and by year, for Greece, Hungary, Italy, Romania and Serbia, 2014-2018 ( $\mathrm{n}=899)$
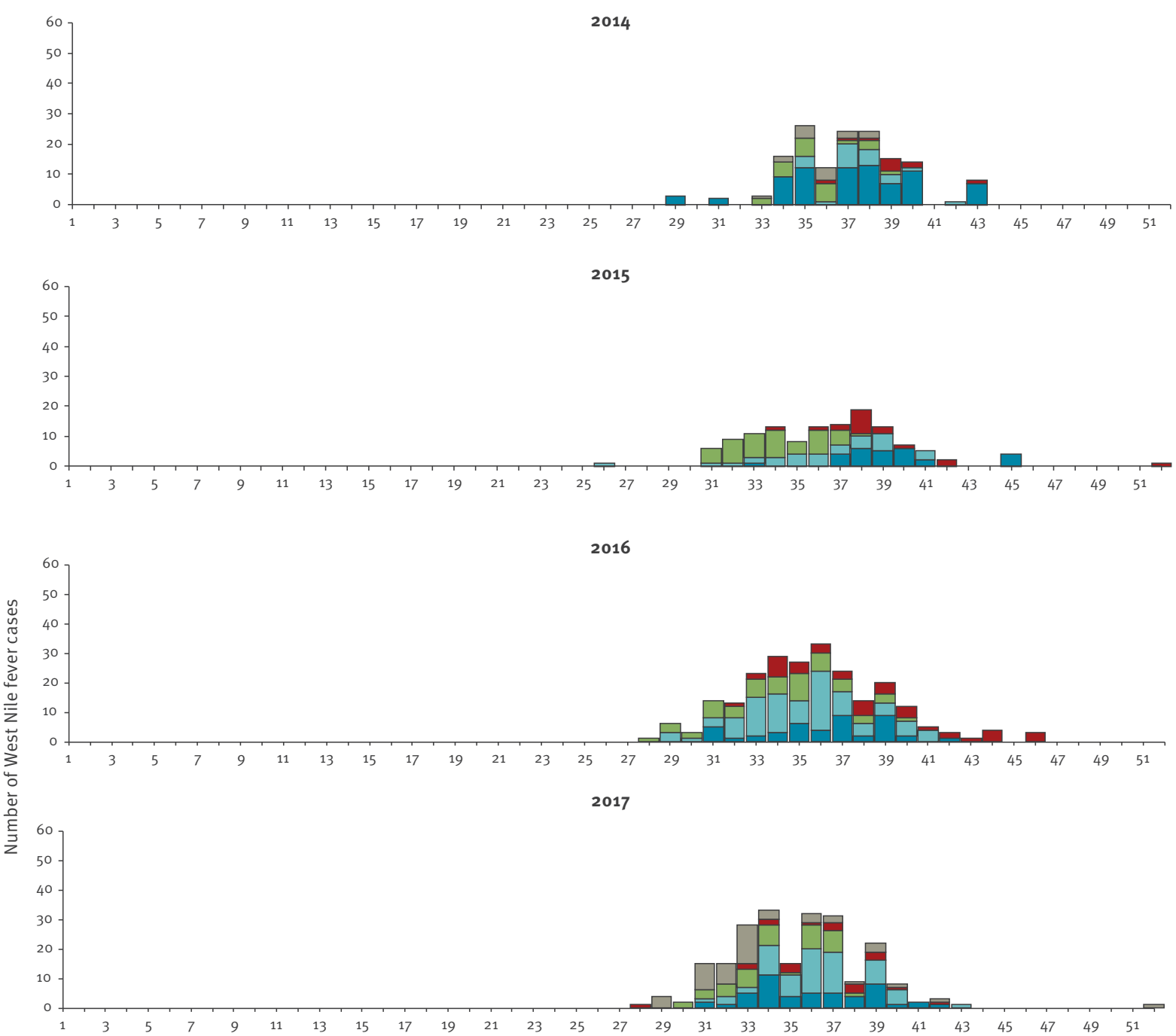

2018

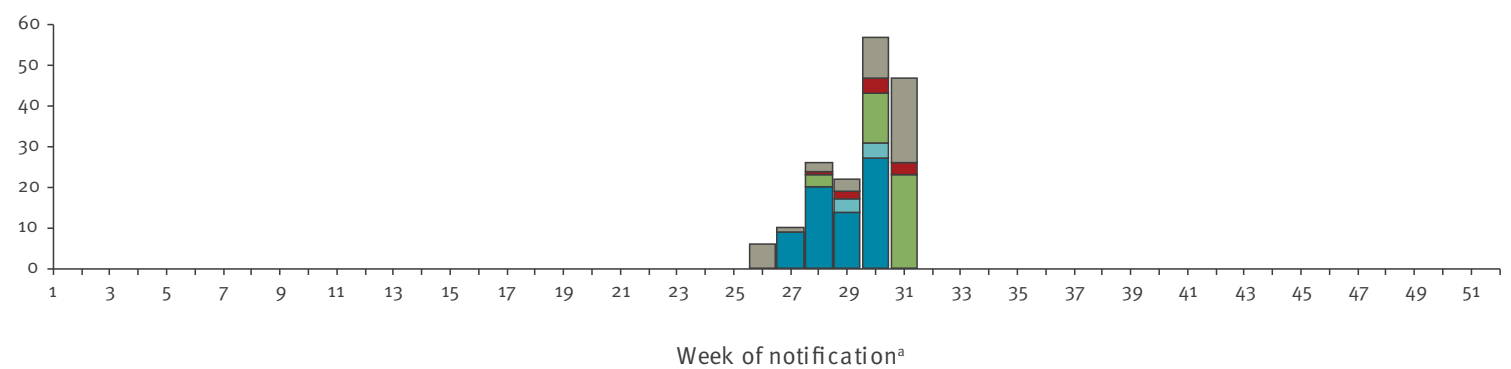

$\square$ Serbia $\square$ Romania $\square$ Italy $\square$ Hungary $\square$ Greece

${ }^{a}$ Week of notification to national authorities or if missing, week of notification to the European Centre for Disease Prevention and Control (ECDC). 


\section{FIGURE 3}

Cumulative number of cases by week of disease onset $\left(n=837^{\mathrm{a}}\right)(\mathrm{A})$ and by week of notification $(\mathrm{n}=899)(\mathrm{B})$, Greece, Hungary, Italy, Romania and Serbia, 2014-2018

A.

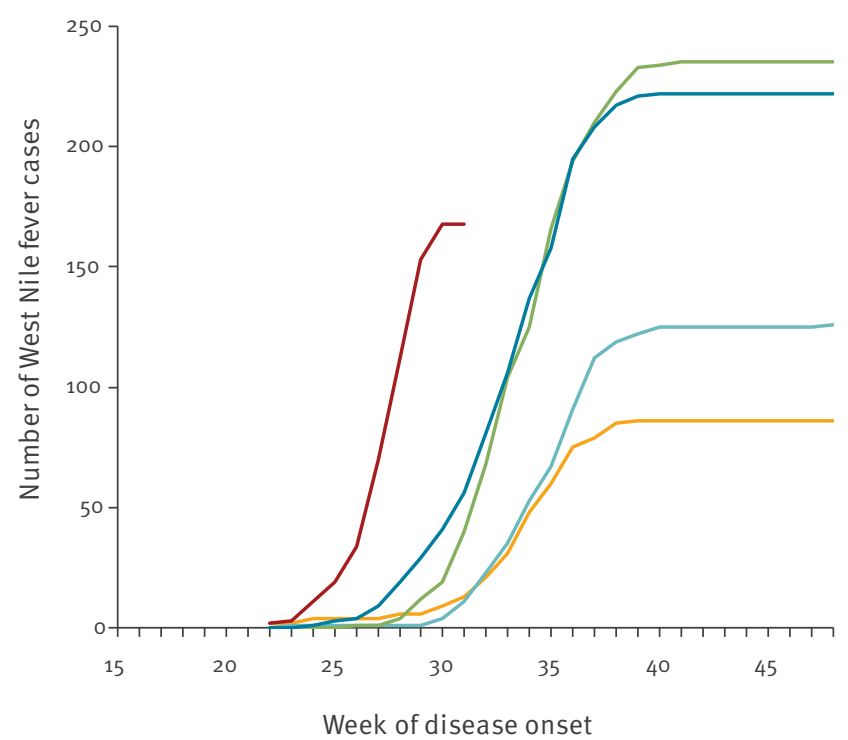

B.

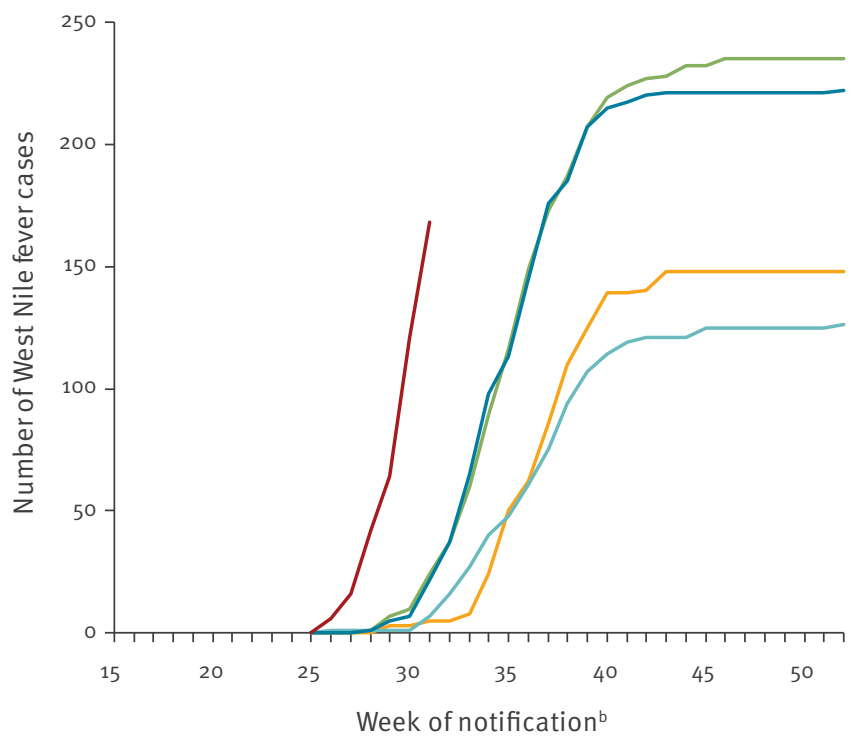

$-2017-2018$

a Of 899 cases notified during 2014-2018, 62 cases were missing information on the week of disease onset for 2014 .

${ }^{b}$ In panel B week of notification to national authorities or if missing, week of notification to the European Centre for Disease Prevention and Control (ECDC).

Programme for WNV surveillance, which includes surveillance of mosquitoes, birds and horses, carried out since 2013 [10]. In 23 of 65 mosquito sampling stations (MSS), established across seven north Serbian districts, WNV-RNA was detected in Culex pipiens species, in week 25 (collecting time, 19-22 June), 2018. That is the highest number of positive MSS ever detected, in those districts (data not shown). This observation could be explained by high temperatures in April and May 2018, with the highest ever recorded average April temperatures since 1888 in Serbia.

Several studies have shown that certain environmental factors, such as temperature and precipitation anomalies, can be predictors for WNF transmission [11-13]. Elevated temperatures can increase virus replication and shorten the incubation period within the mosquito, which can facilitate virus circulation and therefore WNV outbreaks [14]. The underlying determinants of this early upsurge, such as specific environmental conditions in 2018, are not fully understood to date. An indepth study of the environmental determinants would be required to assess the association of WNF and the observed climate pattern over a longer time period in Europe.

The early start of the WNF transmission season observed in 2018 should prompt early awareness raising among clinicians and public health authorities, as the observed pattern might constitute an early sign of a season with larger outbreaks if environmental conditions remain favourable for WNV transmission. The occurrence and extent of outbreaks, however, depend on numerous factors and the situation at present does not necessarily mean that a large outbreak will happen. As the first disease onset this year occurred at the end of May, the previous assumption that the WNF season and the related period of enhanced real-time monitoring of WNF in Europe is typically from mid-June to November, may have to be reconsidered.

Note

*This designation is without prejudice to positions on status, and is in line with United Nations Security Council Resolution 1244/99 and the International Court of Justice Opinion on the Kosovo Declaration of Independence. 


\section{FIGURE 4}

Distribution of regions at NUTS 3 level reporting at least one case of West Nile fever, Europe, 2014-2018

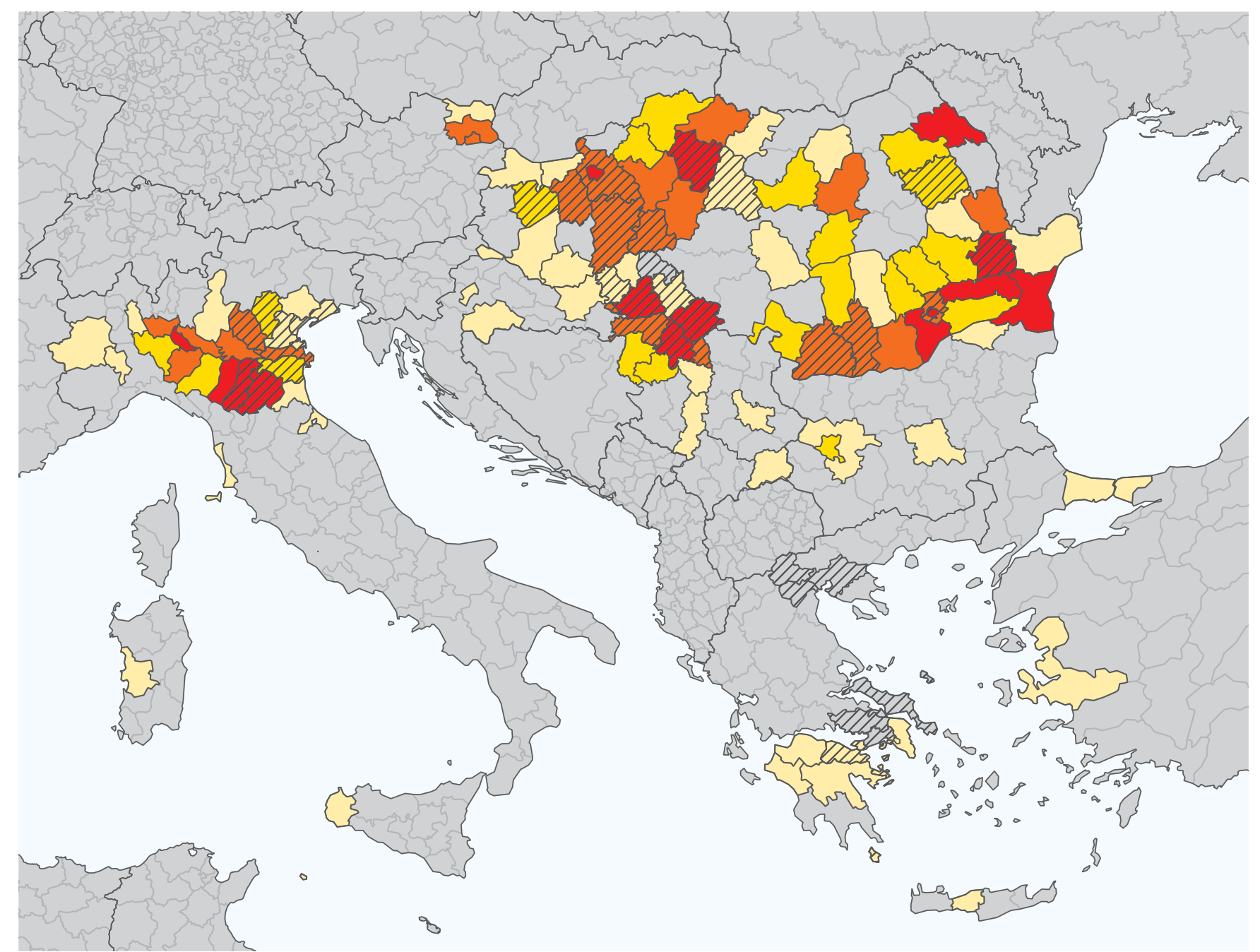

Legend

Administrative boundary

$\square$ National

Number of years with WNF cases (2014-2017)

$\square$ Region at NUTS 3 level

$\square$ One year

$\square$ Two years

WNF affected area at NUTS 3 level

$\square$ Three years

With reported West Nile fever cases in 2018

Four years

NUTS: Nomenclature of Territorial Units for Statistics; WNF: West Nile fever. 


\section{Acknowledgements}

The authors would like to thank:

-Catalin Albu, Alexandru Sache and Marius Valentin Valcu (ECDC) for their support in data management. Vedran Martinovic for his support in uploading data from Serbia to TESSy. -Dragoslav Domanovic and Olivier Briet (ECDC) for revision of the manuscript.

- Anna Nagy (National Public Health Institute, Hungary) and Orsolya Nagy (National Public Health Institute, Hungary) for their support in performing serological and PCR analysis of human samples in Hungary.

- Annita Vakali and Theano Georgakopoulou from the Hellenic Center for Disease Control \& Prevention (HCDCP) for their support in WNF surveillance. Prof Anna Papa from the Hellenic National Reference Centre for Arboviruses and Haemorrhagic Fever viruses, Prof Athanasios Tsakris and Maria Mavrouli from the Department of Microbiology, Medical School of Athens, and Andreas Mentis and Maria Emmanouil from the Hellenic Pasteur Institute, for their support in timely diagnosis and reporting of the diagnosed cases to the HCDCP.

- F. Riccardo for revision of the manuscript and for verification of the data from Italy. C. Rizzo; G. Venturi; M. Di Luca, P. Pezzotti, G. Rezza (Department of Infectious Diseases, Istituto Superiore di Sanità, Rome, Italy); F. Monaco, G. Savini F. Iapaolo (Istituto Zooprofilattico, Teramo, Italy); G. Marrano, I. Pati, S. Pupella; Giancarlo Maria Liumbruno (National Blood Centre, Istituto Superiore di Sanità, Rome, Italy); L. Lombardini, M. Vincenzo, N. Costa (National Transplant Centre, Istituto Superiore di Sanità, Rome, Italy); P. Parodi; F. Maraglino; (Ministry of Health, Rome, Italy); Italian Regional Authorities, Italian Regional Reference Laboratories for Arboviruses, Italian Local Health Units and Municipalities for verification of the data from Italy.

- all clinicians and laboratory experts contributing in early diagnosis and reporting of WNF cases on country level.

\section{Conflict of interest}

None declared.

\section{Authors' contributions}

JMH and JJY analysed the data, wrote the manuscript and coordinated the preparation of the manuscript. CMG supported data collection and reviewed the final manuscript. EM, AB, AS, DP and MBD collected and provided data and reviewed the final manuscript. BS analysed the data, contributed to the outline of the manuscript and reviewed the final manuscript. All authors approved the manuscript.

\section{References}

1. European Commission. Commission Implementing Decision 2012/506/EU amending Decision 2002/253/EC laying down case definitions for reporting communicable diseases to the Community network under Decision No $2119 / 98 / E C$ of the European Parliament and of the Council. 2012. [Accessed 7 Aug 2018]. Available from: http://eur-lex.europa.eu/legal-content/ EN/TXT/PDF/?uri=CELEX:32012D0506\&qid $=1428573336660 \& f$ rom $=$ EN\#page $=38$

2. Zehender G, Veo C, Ebranati E, Carta V, Rovida F, Percivalle $\mathrm{E}$, et al. Reconstructing the recent West Nile virus lineage 2 epidemic in Europe and Italy using discrete and continuous phylogeography. PLoS One. 2017;12(7):e0179679. https://doi. org/10.1371/journal.pone.0179679 PMID: 28678837
3. Centers for Disease Control and Prevention (CDC). West Nile Virus transmission. Updated 14 December 2017. Atlanta: CDC. [Accessed 7 Aug 2018]. Available from: http://www.cdc.gov/ westnile/transmission/index.html

4. Sambri V, Capobianchi M, Charrel R, Fyodorova M, Gaibani P, Gould E, et al. West Nile virus in Europe: emergence, epidemiology, diagnosis, treatment, and prevention. Clin Microbiol Infect. 2013;19(8):699-704. https://doi. org/10.1111/1469-0691.12211 PMID: 23594175

5. Zeller HG, Schuffenecker I. West Nile virus: an overview of its spread in Europe and the Mediterranean basin in contrast to its spread in the Americas. Eur J Clin Microbiol Infect Dis. 2004;23(3):147-56. https://doi.org/10.1007/s10096-003-10851 PMID: 14986160

6. Calistri P, Giovannini A, Hubalek Z, Ionescu A, Monaco F, Savini G, et al. Epidemiology of West Nile in Europe and in the Mediterranean basin. Open Virol J. 2010;4:29-37. https://doi. org/10.2174/1874357901004010029 PMID: 20517490

7. European Commission. COMMISSION DIRECTIVE 2014/110/ EU of 17 December 2014 amending Directive 2004/33/EC as regards temporary deferral criteria for donors of allogeneic blood donations 2014. [Accessed 31 Jul 2018]. Available from: http://eur-lex.europa.eu/legal-content/EN/TXT/?uri=0J\%3AJOL 2014_366_R_0011

8. European Center for Disease Prevention and Control (ECDC). Weekly updates: 2018 West Nile fever transmission season. Stockholm: ECDC; 2018. Available from: https://ecdc.europa. eu/en/west-nile-fever/surveillance-and-disease-data/ disease-data-ecdc

9. Copernicus Climate Change Service. Monthly summaries of precipitation, relative humidity and soil moisture 2018 . [Accessed 31 Jul 2018]. Available from: https://climate. copernicus.eu/monthly-summaries-precipitation-relativehumidity-and-soil-moisture

10. Kemenesi G, Krtinić B, Milankov V, Kutas A, Dallos B, Oldal $M$, et al. West Nile virus surveillance in mosquitoes, April to October 2013, Vojvodina province, Serbia: implications for the 2014 season. Euro Surveill. 2014;19(16):20779. https://doi. org/10.2807/1560-7917.ES2014.19.16.20779 PMID: 24786260

11. Groen TA, L'Ambert G, Bellini R, Chaskopoulou A, Petric D, Zgomba M, et al. Ecology of West Nile virus across four European countries: empirical modelling of the Culex pipiens abundance dynamics as a function of weather. Parasit Vectors. 2017;10(1):524. https://doi.org/10.1186/s13071-017-2484-y PMID: 29070056

12. Tran A, Sudre B, Paz S, Rossi M, Desbrosse A, Chevalier $\mathrm{V}$, et al. Environmental predictors of West Nile fever risk in Europe. Int J Health Geogr. 2014;13(1):26. https://doi. org/10.1186/1476-072X-13-26 PMID: 24986363

13. Vogels CBF, Göertz GP, Pijlman GP, Koenraadt CJM. Vector competence of northern and southern European Culex pipiens pipiens mosquitoes for West Nile virus across a gradient of temperatures. Med Vet Entomol. 2017;31(4):358-64. https:// doi.org/10.1111/mve.12251 PMID: 28752627

14. Paz S, Malkinson D, Green MS, Tsioni G, Papa A, Danis K, et al. Permissive summer temperatures of the 2010 European West Nile fever upsurge. PLoS One. 2013;8(2):e56398. https://doi. org/10.1371/journal.pone.0056398 PMID: 23431374 License and copyright

\section{License and copyright}

This is an open-access article distributed under the terms of the Creative Commons Attribution (CC BY 4.0) Licence. You may share and adapt the material, but must give appropriate credit to the source, provide a link to the licence, and indicate if changes were made.

This article is copyright of the Author or their affiliated institutions, 2018. 